\title{
Association of secreted frizzled-related protein 4 (SFRP4) with type 2 diabetes in patients with stable coronary artery disease
}

\author{
Michael M Hoffmann ${ }^{1 *}$, Christian Werner ${ }^{2+}$, Michael Böhm ${ }^{2}$, Ulrich Laufs ${ }^{2}$ and Karl Winkler ${ }^{1}$
}

\begin{abstract}
Background: Secreted frizzled-related proteins (SFRP) are regulators of Wnt-signalling. SFRP4 has been shown to regulate insulin exocytosis and is overexpressed in type 2 diabetes mellitus.

Here we characterized the relation of SFRP4 to glucose and triglyceride metabolism and outcomes in patients with

stable coronary artery disease on statin treatment in the prospective Homburg Cream \& Sugar Study

(NCT00628524).

Methods: Fasting SFRP4 concentrations were measured by ELISA in 504 consecutive patients with stable CAD confirmed by angiography.

Results: The median age was 68 years and $83 \%$ of patients were male. Oral glucose tolerance tests were performed in all patients without known diabetes for metabolic characterization. $24.4 \%$ of patients showed normal glucose tolerance, $29.4 \%$ impaired glucose tolerance and $46.2 \%$ diabetes mellitus. SFRP4 concentrations correlated with insulin $(R=0.153, p=0.001)$, HbA1c $(R=0.166, p<0.0001)$, fasting triglycerides $(R=0.113, p=0.011)$ and higher triglycerides after lipid challenge (postprandial triglycerides $R=0.124, p=0.005 ; A \cup C R=0.134, p=0.003$ ). Higher SFRP4 concentrations were associated with type 2 diabetes, metabolic syndrome, and severity of diabetes. The primary outcome was the composite of cardiovascular death and cardiovascular hospitalization within 48 months follow-up. Comparison of event-free survival between SFRP4 tertiles showed that SFRP4 concentrations were not predictive for cardiovascular outcome.

Conclusions: SFRP4 concentrations are associated with impaired glucose and triglyceride metabolism but do not predict cardiovascular outcome in patients with stable coronary artery disease on treatment.
\end{abstract}

Keywords: SFRP4, Type 2 diabetes mellitus, Coronary artery disease

\section{Background}

Type 2 diabetes (T2DM) is a chronic, progressive disease characterized by insulin resistance and beta-cell dysfunction resulting in the decline of insulin production and secretion. T2DM is contributing to a significant morbidity and mortality, it affects more than 300 million individuals worldwide and the prevalence is still increasing, with the expectation of 439 million adults affected by 2030 [1].

Wnt (Wingless and Int-1) signalling is a conserved pathway involved in embryonic development, the self-renewal

\footnotetext{
* Correspondence: michael.marcus.hoffmann@uniklinik-freiburg.de

${ }^{\dagger}$ Equal contributors

'Institute of Clinical Chemistry and Laboratory Medicine, University Medical

Center Freiburg, Freiburg, Germany

Full list of author information is available at the end of the article
}

of adult tissue and in carcinogenesis [2,3]. Several Wnt pathway components are associated with lipid and glucose metabolism and thereby influence the development of diabetes. Variations in the Wnt co-receptors LRP5 and LRP6 are associated with type 1 diabetes [4] and early coronary disease and the metabolic syndrome [5]. TCF7L2, a transcription factor at the end of the Wnt-signalling cascade is the most prominent hit in genome-wide association studies exploring the genetics of T2DM [6]. TCF7L2 might be a key regulator of proinsulin synthesis, processing and possibly clearance [7] and is involved in the regulation of incretin production [8]. 
Wnt-signalling is modulated at several levels. A number of secreted proteins, including secreted frizzled-related proteins (SFRPs), bind Wnts, thereby modulating their action [2]. SFRPs share homology with the extracellular domain of frizzled proteins but lack the transmembrane and intracellular components that are necessary for signalling transduction. SFRPs antagonize Wnt-signalling by competitively binding to Wnts or to their receptors in the plasma membrane. In humans, the SFRP family consists of 5 members, termed SFRP1-5. Several SFRPs have been described as adipokines with different roles in adipogenesis [9-11] and SFRP4 as a regulator of insulin exocytosis in murine and human islet cells [12]. Moreover, the authors presented data showing an association of SFRP4 serum levels with insulin resistance and T2DM. Interestingly, in two small cohorts SFRP4 was elevated several years before clinical diagnosis of diabetes, assuming the possibility of SFRP4 as an early diabetes marker [12].

Another SFRP, which has been associated with type 2 diabetes, is SFRP5. However, the role of SFRP5 in type 2 diabetes is still controversial. Three studies describe an association of higher SFRP5 levels with type 2 diabetes $[13,14]$ or insulin resistance in non-diabetic subjects [15], whereas two studies show the opposite effect, lower SFRP5 levels in subjects with prediabetes or type 2 diabetes in comparison to controls $[16,17]$.

To assess the above described association of SFRP4 serum levels with insulin resistance and T2DM we analysed SFRP4 in 504 patients with clinically stable coronary artery disease from the prospective observational Homburg Cream and Sugar study [18]. The strength of the Homburg Cream \& Sugar Study is the detailed clinical and metabolic characterisation of the patients, including a sophisticated metabolic test protocol to analyse glucose and triglyceride metabolism.

\section{Methods \\ Study design}

Methods of the Homburg Cream and Sugar study (NCT00628524) have been described in detail [18] elsewhere. Briefly, from February 2008 to July 2009, 504 consecutive patients with clinically stable coronary artery disease (CAD) documented by angiography were enrolled in this prospective, observational study. Institutional approval was provided by the ethics committee of the Saarland (number 170/07) and all participants gave written informed consent.

Metabolic syndrome, impaired glucose tolerance and diabetes were defined according to current recommendations $[19,20]$ : The metabolic syndrome was considered when three of the following criteria were positive: elevated waist circumference (men $\geq 94 \mathrm{~cm}$, women $\geq 80 \mathrm{~cm}$ ), elevated fasting TG $(\geq 150 \mathrm{mg} / \mathrm{dl})$, low HDL-cholesterol (men $<40 \mathrm{mg} / \mathrm{dl}$, women $<50 \mathrm{mg} / \mathrm{dl}$ ), elevated fasting glucose ( $\geq 110 \mathrm{mg} / \mathrm{dl}$ or drug treatment for diabetes) or elevated blood pressure $(\geq 140 \mathrm{mmHg}$ systolic or $\geq 90 \mathrm{mmHg}$ diastolic treatment naïve or on anti-hypertensive treatment). Type 2 diabetes was defined based on validated physician diagnosis and newly diagnosed diabetes according to the guidelines of the American Diabetes Association when fasting glucose was $\geq 126 \mathrm{mg} / \mathrm{dl}$, HbA1c $>6.5 \%$ and/ or 2-hour glucose was $\geq 200 \mathrm{mg} / \mathrm{l}$. Laboratory measurements were performed at the core facilities of the Medical University of the Saarland.

Follow-up data were obtained by standardized telephone interviews after 12, 24, and 48 months. The primary outcome was the composite of cardiovascular death and cardiovascular hospitalisation for acute coronary syndrome (for definitions see [21,22]) or hospitalization for unplanned, symptom-induced coronary angiography and revascularization including bypass surgery.

\section{SFRP4 assay}

Fasting SFRP4 concentrations were measured in duplicate by an enzyme-linked immunosorbent assay produced by Phadia GmbH (Freiburg, Germany) in diluted (1:11) fasting serum samples according to the manufacturer's instructions. A 4-point standard curve $(0,0-0,2-1,0-5,0 \mathrm{ng} / \mathrm{ml})$ was created using lyophilized recombinant human SFRP4. Samples that were out of the range of the standard curve were further diluted (1:5) and measured again. Intra-assay and inter-assay variations were $6.8 \%$ and $9.1 \%$, respectively.

\section{Statistical analysis}

Kolmogorov-Smirnov tests showed that continuous baseline variables were not normally distributed in the cohort. Data are there foreshown as median and interquartile (25\%-75\%) range (Table 1). SFRP4 serum concentrations were not evenly distributed; therefore, $\log ($ SFRP4) was used for all analyses. Patients were stratified by $\log ($ SFRP4) tertiles to analyse differences in baseline characteristics using ANOVA for continuous and Fisher's exact tests for categorical variables (Table 2). Furthermore, $\log$ (SFRP4) concentrations were compared with continuous variables by twosided Pearson correlation and linear regression analyses and between strata of categorical variables by Spearman's rank correlation (Tables 3 and 4). The number of endpoints between $\log$ (SFRP4) tertiles was compared in cross-tables using Chi2 tests (Table 5) and time-to-event analyses were performed with Kaplan-Meier-Curves using log-rank tests (Figure 1) and univariate Cox proportional regression analyses to calculate hazard ratios (HR) and 95\% confidence intervals (95\%-CI). To this end, the lower log(SFRP4) tertile was set as reference category (HR 1.0) and the upper tertile as the comparator (Table 6).

The null hypothesis was rejected and statistical significance was assumed at p-values $<0.05$. All statistical analyses were performed with SPSS software version 20.0. 
Table 1 Baseline characteristics of the study cohort

\begin{tabular}{|c|c|}
\hline & $\begin{array}{l}\text { Percentage (number) } \\
\text { median (IQR) }\end{array}$ \\
\hline $\mathrm{N}$ & 504 \\
\hline Age (years) & $68(59,74)$ \\
\hline Male & $83.3(420)$ \\
\hline \multicolumn{2}{|l|}{ Clinical characteristics } \\
\hline Smoking (active) & $18.8(99)$ \\
\hline Alcohol regularly & $23.8(120)$ \\
\hline Positive family history & $31(156)$ \\
\hline Hyperlipidemia & $86.3(435)$ \\
\hline Diabetes mellitus (treated) & $32.7(165)$ \\
\hline Arterial hypertension & $92.7(467)$ \\
\hline Systolic blood pressure $(\mathrm{mm} \mathrm{Hg})$ & $125(120,140)$ \\
\hline Diastolic blood pressure $(\mathrm{mm} \mathrm{Hg})$ & $80(70,80)$ \\
\hline Body mass index $\left(\mathrm{kg} / \mathrm{m}^{2}\right)$ & $28(26,31)$ \\
\hline Waist circumference $(\mathrm{cm})$ & $102(73,139)$ \\
\hline Waist-to-hip ratio & $1.0(0.96,1.05)$ \\
\hline \multicolumn{2}{|l|}{ Metabolic characterization } \\
\hline Normal glucose tolerance & $24.4(123)$ \\
\hline Impaired glucose tolerance & $28.4(143)$ \\
\hline $\begin{array}{l}\text { Diabetes mellitus (treated \& newly } \\
\text { diagnosed) }\end{array}$ & $47.2(238)$ \\
\hline Metabolic syndrome & $64.9(327)$ \\
\hline Fasting glucose (mg/dl) & $110(101,132)$ \\
\hline HOMA index $\left(\mathrm{mg} / \mathrm{dl}^{*} \mu \mathrm{lU} / \mathrm{ml}\right)$ & $2.3(1.3,4.1)$ \\
\hline $\operatorname{HbA1c}(\%)^{*}$ & $5.8(5.5,6.5)$ \\
\hline Total cholesterol (mg/dl) & $167(143,199)$ \\
\hline HDL cholesterol (mg/dl) & $43(35,53)$ \\
\hline LDL cholesterol (mg/dl) & $100(80,129)$ \\
\hline Fasting triglycerides $(\mathrm{mg} / \mathrm{dl})$ & $126(96,175)$ \\
\hline Postprandial triglycerides, maximum (mg/dl) & $237(175,347)$ \\
\hline Postprandial triglycerides, AUC (mg/dl) & $905(665,1278)$ \\
\hline C-reactive protein (mg/l) & $2.2(0.9,4.9)$ \\
\hline SFRP4 ( $\mu \mathrm{g} / \mathrm{l})$ & $11.21(9.17,13.86)$ \\
\hline
\end{tabular}

Categorical variables are shown as rate (number). Plus-minus values are depicted as median (interquartile range). Active smoking was regular tobacco use at or within 12 months prior to enrolment. Regular alcohol use was consumption of any alcoholic beverage $>3$ times/week. The HOMA (Homeostasis Model Assessment) index is the fasting glucose concentration (in milligrams per deciliter) multiplied by the fasting insulin concentration (in microunits per milliliter) divided by 405 .

${ }^{*} \mathrm{HbA} 1 \mathrm{c}$ was missing in 23 patients.

\section{Results}

For this study $\mathrm{N}=504$ patients with angiographically confirmed stable CAD were enrolled. The median age was 68 years and $83 \%$ of the patients were male. $32.7 \%$ of the patients had a history of T2DM, after oral glucose tolerance test $13.5 \%(\mathrm{~N}=68)$ were newly diagnosed for T2DM and an impaired glucose tolerance was seen in
$29.4 \%$, thus in this cohort only $24.4 \%$ of the patients showed a normal glucose tolerance (Table 1). SFRP4 serum levels were in the range of $3.64-41.2 \mu \mathrm{g} / \mathrm{l}$, with a median of $11.21 \mu \mathrm{g} / \mathrm{l}$. SFRP4 serum concentrations were not evenly distributed (Kolmogorov-Smirnov-Z 4.854, p <0.001); therefore we used $(\log )$ SFRP4 for the following analysis.

The patient characteristics in the SFRP4 tertiles are displayed in Table 2 and Figure 1. Patients in the highest SFRP4 tertile were older and more often had a history of myocardial infarction, percutaneous intervention or bypass operation. Waist circumference and BMI were increasing significantly from the lowest to the highest tertile. Patients in the first tertile showed significantly lower levels of fasting insulin, HbA1c, fasting and postprandial triglycerides and in accordance to this the fraction of patients with T2DM or metabolic syndrome in the first tertile was considerably lower in comparison to the other tertiles. In correlation analyses (Table 3) SFRP4 concentrations correlated with $\mathrm{HbA1c}$, fasting insulin, BMI, fasting and postprandial triglycerides. Comparison of SFRP4 concentrations between strata of categorical variables showed that SFRP4 levels were higher in patients with metabolic syndrome, insulin therapy, diabetes and a history of myocardial infarction or PCI (Table 4).

Within 4 years follow-up 287 patients survived event-free and 217 patients experienced a primary cardiovascular endpoint such as acute coronary syndromes, major adverse cardiovascular events and cardiovascular death + non-fatal myocardial infarction. Interestingly, the number of patients experiencing a stroke/transitory ischemic attack (TIA) was significantly higher in the upper SFRP4 tertile, both in descriptive as well as in univariate time-to-event analyses (Tables 5 and 6). However, the association of sFPR4 was not independent of other risk factors, because significance was rapidly lost upon multivariable adjustment (not shown).

\section{Discussion}

The importance and burden of T2DM for our health system is permanently increasing, despite all efforts in primary prevention. Because it is a progressive disease which does not cause specific symptoms for many years diagnosis at an early state is of outmost importance. Usually, the diagnosis starts with measurement of fasting plasma glucose or HbA1c, the advantages and disadvantages of HbA1c measurement are discussed in a WHO report from 2011 [23]. Oral glucose tolerance test is still the gold standard but due to the time consuming procedure not feasible everywhere. With the help of the OGTT we were able to detect $68(13.5 \%)$ previously unknown patients with diabetes in the HCS study, supporting the observation of a high estimated number of unreported cases in secondary prevention cohorts and the general population [24]. 
Table 2 Baseline characteristics, stratified by tertiles of (log)SFRP4

\begin{tabular}{|c|c|c|c|c|}
\hline \multicolumn{5}{|c|}{ (log) SFRP4 Tertiles } \\
\hline & 1 & 2 & 3 & \\
\hline (log)SFRP4 range & $<0.99$ & $0.99-1.11$ & $>1.11$ & $p$-Value \\
\hline Group size & $33.3(168)$ & $33.3(168)$ & $33.3(168)$ & \\
\hline Age (years) & $65.2 \pm 0.7$ & $65.8 \pm 0.8$ & $68.2 \pm 0.8$ & 0.017 \\
\hline Male & $86.3(145)$ & $85.7(144)$ & $78.0(131)$ & 0.068 \\
\hline \multicolumn{5}{|l|}{ Medical history } \\
\hline Previous myocardial infarction & $35.7(60)$ & $44.6(75)$ & $51.8(87)$ & 0.014 \\
\hline $\mathrm{PCl}$ & $57.1(96)$ & $66.7(112)$ & $76.8(129)$ & 0.001 \\
\hline Bypass operation & $7.1(12)$ & $14.3(24)$ & $16.1(27)$ & 0.03 \\
\hline Previous stroke or TIA & $6.0(10)$ & $12.5(21)$ & $13.1(22)$ & 0.065 \\
\hline Peripheral artery disease & $6.5(11)$ & $10.1(17)$ & $10.7(18)$ & 0.37 \\
\hline \multicolumn{5}{|l|}{ Clinical characteristics } \\
\hline Smoking & $21.4(36)$ & $20.8(35)$ & $14.3(24)$ & 0.18 \\
\hline Alcohol regularly & $27.4(46)$ & $25.0(42)$ & $19.0(32)$ & 0.18 \\
\hline Positive family history & $31.5(53)$ & $29.2(49)$ & $32.1(54)$ & 0.79 \\
\hline Arterial hypertension & $88.7(149)$ & $94.0(158)$ & $95.2(160)$ & 0.095 \\
\hline Systolic BP (mmHg) & $124.3 \pm 1.2$ & $127.0 \pm 1.2$ & $128.2 \pm 1.3$ & 0.067 \\
\hline Diastolic BP (mmHg) & $74.0 \pm 0.7$ & $74.9 \pm 0.7$ & $74.8 \pm 0.8$ & 0.62 \\
\hline $\mathrm{BMI}\left(\mathrm{kg} / \mathrm{m}^{2}\right)$ & $27.9 \pm 0.3$ & $29.4 \pm 0.3$ & $29.3 \pm 0.4$ & 0.002 \\
\hline Waist circumference $(\mathrm{cm})$ & $100.9 \pm 0.8$ & $104.9 \pm 0.9$ & $104.9 \pm 0.9$ & 0.001 \\
\hline Waist-to-hip-ratio & $1.00 \pm 0.0$ & $1.00 \pm 0.0$ & $1.01 \pm 0.0$ & 0.36 \\
\hline \multicolumn{5}{|l|}{ Metabolic characterization } \\
\hline Normal glucose tolerance & $32.1(54)$ & $20.2(34)$ & $20.8(35)$ & 0.017 \\
\hline Impaired glucose tolerance & $29.8(50)$ & $28.6(48)$ & $26.8(45)$ & 0.84 \\
\hline Diabetes mellitus & $38.1(64)$ & $51.2(86)$ & $52.4(88)$ & 0.014 \\
\hline Metabolic syndrome & $50.6(85)$ & $72.0(121)$ & $72.0(121)$ & $<0.0001$ \\
\hline Fasting glucose (mg/dl) & $118.6 \pm 2.5$ & $119.5 \pm 2.3$ & $125.0 \pm 2.6$ & 0.15 \\
\hline Fasting insulin ( $\mu \mathrm{IU} / \mathrm{ml})$ & $8.73 \pm 0.6$ & $11.41 \pm 0.9$ & $12.69 \pm 1.1$ & 0.007 \\
\hline HOMA index & $2.70 \pm 0.24$ & $3.64 \pm 0.36$ & $4.33 \pm 0.55$ & 0.018 \\
\hline $\operatorname{HbA1c}(\%)^{*}$ & $6.05 \pm 0.1$ & $6.09 \pm 0.1$ & $6.40 \pm 0.1$ & 0.011 \\
\hline Total cholesterol (mg/dl) & $175.0 \pm 2.8$ & $171.2 \pm 3.2$ & $170.9 \pm 3.0$ & 0.55 \\
\hline HDL cholesterol (mg/dl) & $46.5 \pm 1.0$ & $43.8 \pm 1.0$ & $43.8 \pm 1.1$ & 0.12 \\
\hline LDL cholesterol (mg/dl) & $107.7 \pm 2.4$ & $105.3 \pm 2.8$ & $101.0 \pm 2.6$ & 0.19 \\
\hline Fasting triglycerides (mg/dl) & $133.9 \pm 5.3$ & $164.6 \pm 15.0$ & $170.0 \pm 9.9$ & 0.043 \\
\hline Postprandial triglyerides, maximum (mg/dl) & $253.5 \pm 9.7$ & $305.4 \pm 19.7$ & $309.9 \pm 14.2$ & 0.015 \\
\hline Postprandial triglycerides, AUC (mg/dl) & $943.8 \pm 36.2$ & $1135.6 \pm 68.5$ & $1160.3 \pm 54.4$ & 0.010 \\
\hline C-reactive protein (mg/l) & $3.65 \pm 0.5$ & $4.90 \pm 0.5$ & $4.99 \pm 0.7$ & 0.16 \\
\hline
\end{tabular}

Categorical variables are shown as rate (number) and continuous values as mean (SEM). TIA denotes transitory ischemic attack. Active smoking was regular tobacco use at or within 12 months prior to enrolment. Regular alcohol use was consumption of any alcoholic beverage $>3$ times/week. The HOMA (Homeostasis Model Assessment) index is the fasting glucose concentration (in milligrams per deciliter) multiplied by the fasting insulin concentration (in microunits per milliliter) divided by 405 .

${ }^{*} \mathrm{HbA} 1 \mathrm{c}$ was missing in 23 patients.

Until now unique markers for the different stages of impaired glucose metabolism are missing, except postprandial plasma glucose. Thus, a recent publication of Mahdi et al. [12] attracted a great deal of attention, cumulating in the title "Mining Genes in Type 2 Diabetic Islets and Finding Gold" of an accompanying editorial [25] and in a computer aided screening for SFRP4 inhibitors [26]. In a set of elegant experiments Mahdi 
Table 3 Correlation of (log)SFRP4 concentration with baseline characteristics

\begin{tabular}{lll}
\hline Parameter & Pearson R & p-Value \\
\hline HbA1c & 0.17 & $<0.0001$ \\
Fasting insulin & 0.15 & 0.001 \\
Body mass index & 0.15 & 0.001 \\
Fasting triglycerides & 0.11 & 0.011 \\
Postprandial triglycerides & 0.12 & 0.005 \\
Postprandial triglycerides AUC & 0.13 & 0.003 \\
Age & 0.09 & 0.053 \\
\hline
\end{tabular}

Continuous baseline variables were compared with (log)SFRP4 concentrations by two-sided Pearson correlation; no significant association between SFRP4 and other than the listed was seen.

et al. showed that SFRP4 impairs insulin release both in vitro in mouse and human islets and in vivo in SFRP4-treated mice. The reduced secretion was explained by decreased expression of L-type and P/Q-type $\mathrm{Ca} 2+$ channels in the islets' cells causing a suppression of insulin exocytosis. This corresponds well to previous published data of Taneera et al. [27], describing a

Table 4 Correlation of (log)SFRP4 concentration with baseline characteristics

\begin{tabular}{|c|c|c|c|c|}
\hline \multirow[t]{2}{*}{ Characteristic } & \multirow[t]{2}{*}{ No. } & Log(SRFP4) & \multirow[t]{2}{*}{ Spearman's Rho } & \multirow[t]{2}{*}{ p-Value } \\
\hline & & Mean \pm SEM & & \\
\hline \multicolumn{3}{|c|}{ Previous myocardial infarction } & 0.13 & 0.007 \\
\hline No & 282 & $1.04 \pm 0.1$ & & \\
\hline Yes & 222 & $1.08 \pm 0.1$ & & \\
\hline \multicolumn{2}{|l|}{ Previous PCl } & & 0.17 & 0.001 \\
\hline No & 167 & $1.03 \pm 0.1$ & & \\
\hline Yes & 337 & $1.07 \pm 0.1$ & & \\
\hline \multicolumn{3}{|c|}{ Previous cardiac bypass operation } & 0.13 & 0.005 \\
\hline No & 441 & $1.05 \pm 0.1$ & & \\
\hline Yes & 63 & $1.10 \pm 0.1$ & & \\
\hline \multicolumn{2}{|l|}{ Previous stroke } & & 0.11 & 0.026 \\
\hline No & 451 & $1.05 \pm 0.1$ & & \\
\hline Yes & 53 & $1.10 \pm 0.2$ & & \\
\hline \multicolumn{2}{|l|}{ T2DM } & & 0.11 & 0.011 \\
\hline No & 266 & $1.04 \pm 0.1$ & & \\
\hline Yes & 238 & $1.07 \pm 0.1$ & & \\
\hline \multicolumn{2}{|l|}{ Insulin therapy } & & 0.17 & 0.001 \\
\hline No & 429 & $1.05 \pm 0.1$ & & \\
\hline Yes & 75 & $1.10 \pm 0.2$ & & \\
\hline \multicolumn{2}{|c|}{ Metabolic syndrome } & & 0.16 & $<0.0001$ \\
\hline No & 177 & $1.02 \pm 0.1$ & & \\
\hline Yes & 327 & $1.08 \pm 0.1$ & & \\
\hline
\end{tabular}

Mean (log)SFRP4 concentrations were compared between strata of categorical variables by Spearman's rank correlation test; no association between SFRP4 and parameters other than the listed.
Table 5 Number of events, stratified by (log)SFRP4 tertiles

\begin{tabular}{|c|c|c|c|c|}
\hline \multicolumn{5}{|c|}{ (log)SFRP4 tertiles } \\
\hline & $<0.99$ & $0.99-1.11$ & $>1.11$ & p-Value \\
\hline & $N=168$ & $N=168$ & $N=168$ & \\
\hline \multicolumn{5}{|c|}{ Event number per tertile } \\
\hline $\begin{array}{l}\text { All primary } \\
\text { endpoints }\end{array}$ & 72 & 69 & 76 & 0.74 \\
\hline $\begin{array}{l}\text { Acute coronary } \\
\text { syndrome }\end{array}$ & 16 & 15 & 26 & 0.11 \\
\hline MACE* & 45 & 40 & 42 & 0.82 \\
\hline Stroke/TIA & 8 & 10 & 19 & 0.049 \\
\hline $\begin{array}{l}\text { Cardiovascular } \\
\text { death + non-fatal Ml }\end{array}$ & 16 & 20 & 16 & 0.71 \\
\hline All-cause death & 9 & 16 & 18 & 0.18 \\
\hline
\end{tabular}

Descriptive statistics (Chi2) were used to compare the number of patients with events between (log)SFRP4 tertiles.

*MACE = Major adverse cardiovascular events (Combination of myocardial

infarction, unplanned revascularization and cardiovascular death).

significant inverse correlation of SFRP4 expression in human pancreatic islets with insulin secretion $(R=-0.28$; $\mathrm{p}=0.03)$. This was supported by in vitro experiments with isolated human pancreatic islets showing that recombinant SFRP4 inhibits insulin secretion by $30 \%$ and cell exocytosis by $50 \%$. Besides the functional characterization of SFRP4 action in islets Mahdi et al. reported a significant correlation of serum SFRP4 concentration with fasting glucose $(\beta=0.142 ; p=0.004)$, reduced insulin sensitivity index $(\beta=-0.176 ; p=0.002)$ and lower disposition index (insulin secretion adjusted for insulin sensitivity; $\beta=-0.186 ; p=0.029$ ) in non-diabetic subjects [12]. Furthermore they described elevated SFRP4 serum levels several years before the clinical diagnosis of T2DM was made, proposing the possibility of SFRP4 as an early risk predictor [12].

In the HCS study we could confirm their observation that T2DM patients are characterized by higher SFRP4 levels. Looking at specific parameters of the glucose metabolism in the HCS study we found for fasting glucose only an insignificant trend towards higher levels in the second and third tertile, whereas we observed a significant positive correlation of SFRP4 serum levels with fasting insulin and HbA1c, a more reliable glucose sensor than fasting glucose. This observation is in part supported by Taneera et al. who described a strong correlation of SFRP4 expression in isolated islet cells with HbA1c levels of the donors [27]. On the other hand at the moment it is not clear to which extend SFRP4 production in islets corresponds to SFRP4 serum levels or vice versa.

We not only observe an association of higher SFRP4 concentrations with T2DM but also with the metabolic syndrome. SFRP4 was associated with higher BMI, waist 


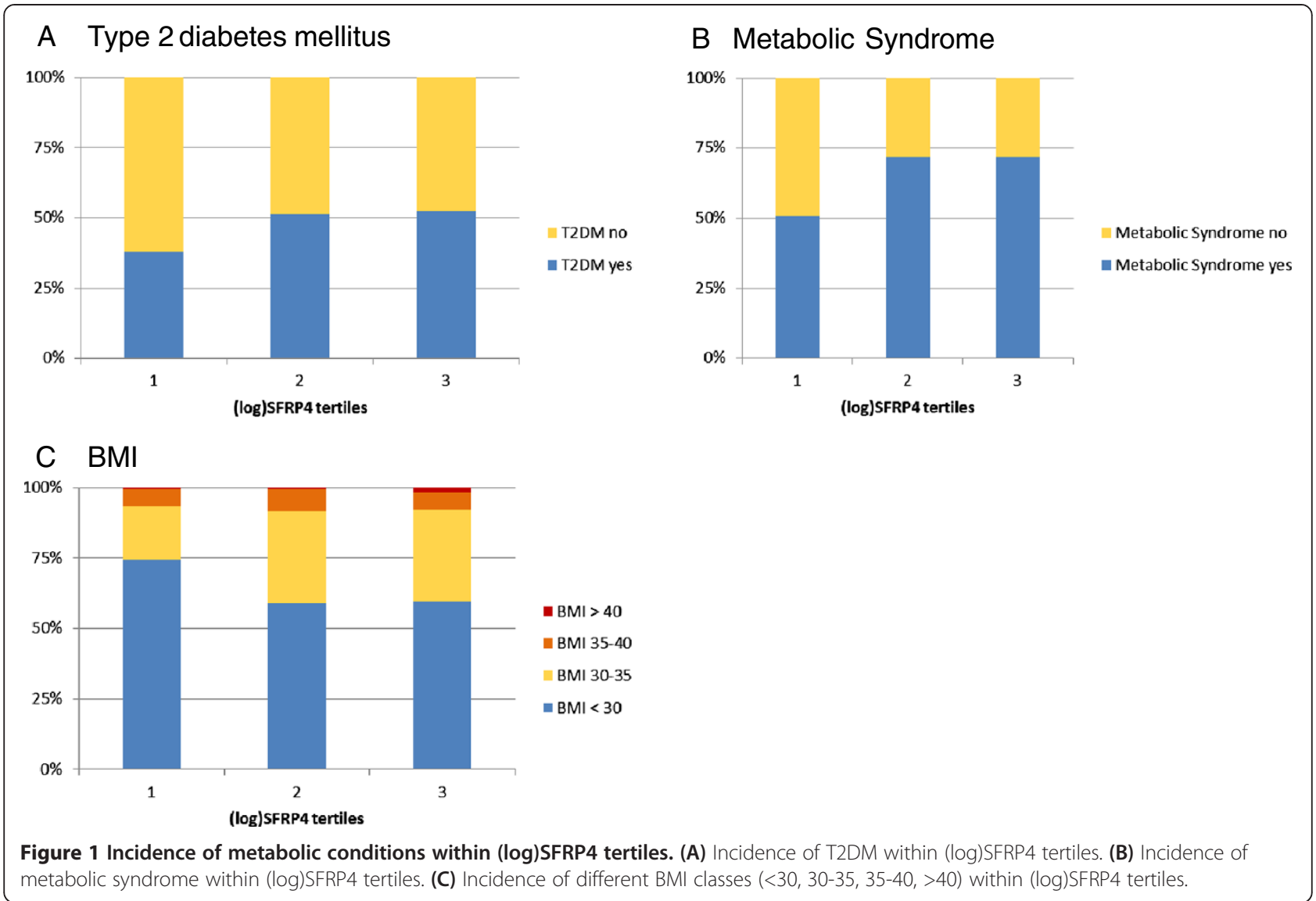

circumference and triglycerides (fasting as well as postprandial after a standardized lipid challenge), all attributes of the metabolic syndrome. Recently, it has been shown that SFRP4 is an adipokine [11]. The expression of SFRP4 is up-regulated in human visceral white adipose tissue of obese subjects and correlates with increased insulin resistance. There is some evidence that SFRP4 might influence the secretion of adiponectin from adipocytes [11]. SFRP4 is also involved in adipogenesis [9]. Park et al. showed that the expression of

Table 6 Number of events, stratified by (log)SFRP4 tertiles

\begin{tabular}{llll}
\hline & HR & $\mathbf{9 5 \% - C l}$ & p-Value \\
\hline All primary endpoints & 1.05 & $0.76-1.45$ & 0.77 \\
Acute coronary syndrome & 1.65 & $0.89-3.08$ & 0.12 \\
MACE* & 0.91 & $0.60-1.38$ & 0.64 \\
Stroke/TIA & 2.45 & $1.07-5.59$ & $\mathbf{0 . 0 3 4}$ \\
Cardiovascular death + non-fatal MI & 0.99 & $0.50-1.99$ & 0.99 \\
All-cause death & 2.02 & $0.91-4.50$ & 0.084
\end{tabular}

Univariate cox proportional hazards regression analyses were used to compare time to events between (log)SFRP4 tertiles. Hazard ratios (HR) and 95\% confidence intervals $(95 \%-\mathrm{Cl})$ are provided for the comparison of the third tertile vs. the first tertile (reference category, $\mathrm{HR}=1.0$ ).

${ }^{*} \mathrm{MACE}=$ Major adverse cardiovascular events (Combination of myocardial infarction, unplanned revascularization and cardiovascular death).
SFRP4 is increased during the adipogenic differentiation of human adipose tissue-derived mesenchymal stem cells and that transfection with siSFRP4 reduced the degree of adipocytic differentiation.

A trigger for the increased expression of SFRP4 in diabetes can be methylglyoxal. Methylglyoxal (MG), also called pyruvaldehyde or 2-oxopropanal, is formed by the degradation of the glycolytic intermediates, dihydroxyacetone phosphate, and glyceraldehyde-3-phosphate [28]. MG reacts with free amino groups of lysine and arginine and with thiol groups of cysteine, forming advanced glycation endproducts. MG concentrations are highly increased in diabetes and are associated with the development of diabetic complications, as demonstrated in several studies [29-32]. Recently, Mori et al. [33] could show that MG can increase SFRP4 gene expression 4-fold in ST2 cells, a mouse bone marrow stromal cell-line. This increase was achieved by an epigenetic derepression of the SFRP4 gene.

Studies describing SFRP4 levels in blood are rare; most groups analyzed SFRP4 on the cellular level or within tumor tissues, supporting the function of SFRP4 as tumor suppressor gene [3]. Besides the study of Madhi et al. [12] and the here presented HCS study only three other groups published SFRP4 serum or plasma levels [34-36]. Berndt et al. described for serum a range of 
$5.5-79.8 \mathrm{ng} / \mathrm{ml}$ in five healthy controls [35], Simpson et al. published for serum a mean of $28.5 \pm 1.7 \mathrm{ng} / \mathrm{ml}$ for 24 unaffected controls and $38.1 \pm 2.3 \mathrm{ng} / \mathrm{ml}$ for patients with high bone mass causing mutations in LRP5 [36]. Jacob et al. were interested in the role of SFRP4 in ovarian cancer and next to SFRP4 expression levels in tumors and cell-lines they published SFRP4 plasma levels which are about 100-fold higher than in the other studies. This discrepancy underlines the need for standardized assays for the necessary studies to further evaluate the role of SFRP4 in diabetes. Besides, the study of Jacob et al. shows that the interpretation of SFRP4 levels demand a detailed evaluation of the patients: In patients with ovarian cancer the reduction in SFRP4 levels could cover the increase associated with the development of diabetes whereas in diabetic patients the increased SFRP4 levels could interfere with the effort to predict the outcome of a newly diagnosed tumor. Due to the exclusion criteria of the HCS study we can be sure that our results were not compromised by cancer.

Within 4 years follow-up nearly half of the patients experienced a primary cardiovascular endpoint. The association of higher SFRP4 concentrations with stroke/TIA seems to be a hit by chance since significance was rapidly lost upon multivariable adjustment.

\section{Limitations}

During follow-up we obtained no fresh blood samples to diagnose the onset of T2DM or a change in SFRP4 concentration. The number of patients with a new onset of T2DM during follow-up was too small for reliable statistical analysis of this parameter.

\section{Conclusions}

This prospective study shows that higher SFRP4 concentrations are associated with T2DM and the metabolic syndrome in well-treated patients with coronary artery disease. SFRP4 concentrations are a novel marker of impaired glucose and triglyceride metabolism, but do not predict cardiovascular outcome in patients with stable coronary artery disease.

Further research is necessary to elucidate the relevance of SFRP4 levels in healthy people and patients with cardiovascular disease and its prognostic value for diabetes and cancer.

\footnotetext{
Abbreviations

AUC: Area under the curve; BMI: Body mass index; BP: Blood pressure; HCS: Homburg cream \& sugar study; HOMA: Homeostasis model assessment; MACE: Major adverse cardiovascular events; OGTT: Oral glucose tolerance test; PCI: Percutaneous coronary intervention; SFRP4: Secreted frizzled related protein 4; T2DM: Type 2 diabetes mellitus; TIA: Transitory ischemic attack; Wnt: Wingless and Int-1.
}

\section{Competing interests}

The authors declare that they have no competing interests.

\section{Authors' contributions}

MMH designed the SFRP substudy, contributed to data acquisition and has written the first draft of the manuscript. CW performed the statistical analysis and helped to draft the manuscript. MB and UL designed and contributed to the funding of the HCS study and critically revised the manuscript. KW participated in interpretation of the data and critically revised the manuscript. All authors read and approved the final manuscript.

\section{Acknowledgements}

The authors are grateful to Professor G. Walz from the Department of Nephrology of the University Medical Center Freiburg for providing the SFRP4 ELISAs and Andrea Schwentek for technical assistance.

The article processing charge was funded by the German Research Foundation (DFG) and the Albert Ludwigs University Freiburg in the funding program Open Access Publishing.

\section{Author details}

${ }^{1}$ Institute of Clinical Chemistry and Laboratory Medicine, University Medical Center Freiburg, Freiburg, Germany. ${ }^{2}$ Klinik für Innere Medizin III,

Universitätsklinikum des Saarlandes, Homburg, Germany.

Received: 8 September 2014 Accepted: 11 November 2014 Published online: 19 November 2014

\section{References}

1. Shaw JE, Sicree RA, Zimmet PZ: Global estimates of the prevalence of diabetes for 2010 and 2030. Diabetes Res Clin Pract 2010, 87(1):4-14.

2. Chien AJ, Conrad WH, Moon RT: A Wnt survival guide: from flies to human disease. J Investig Dermatol 2009, 129(7):1614-1627.

3. Surana R, Sikka S, Cai W, Shin EM, Warrier SR, Tan HJ, Arfuso F, Fox SA, Dharmarajan AM, Kumar AP: Secreted frizzled related proteins: implications in cancers. Biochim Biophys Acta 2014, 1845(1):53-65.

4. Twells RC, Mein CA, Payne F, Veijola R, Gilbey M, Bright M, Timms A, Nakagawa Y, Snook H, Nutland S, Rance HE, Carr P, Dudbridge F, Cordell HJ, Cooper J, Tuomilehto-Wolf E, Tuomilehto J, Phillips M, Metzker M, Hess JF, Todd JA: Linkage and association mapping of the LRP5 locus on chromosome 11q13 in type 1 diabetes. Hum Genet 2003, 113(2):99-105.

5. Mani A, Radhakrishnan J, Wang H, Mani MA, Nelson-Williams C, Carew KS, Mane S, Najmabadi H, Wu D, Lifton RP: LRP6 mutation in a family with early coronary disease and metabolic risk factors. Science 2007, 315(5816):1278-1282.

6. Grant SF, Thorleifsson G, Reynisdottir I, Benediktsson R, Manolescu A, Sainz J, Helgason A, Stefansson H, Emilsson V, Helgadottir A, Styrkarsdottir U, Magnusson KP, Walters GB, Palsdottir E, Jonsdottir T, Gudmundsdottir T, Gylfason A, Saemundsdottir J, Wilensky RL, Reilly MP, Rader DJ, Bagger Y, Christiansen C, Gudnason V, Sigurdsson G, Thorsteinsdottir U, Gulcher JR, Kong A, Stefansson K: Variant of transcription factor 7-like 2 (TCF7L2) gene confers risk of type 2 diabetes. Nat Genet 2006, 38(3):320-323.

7. Zhou Y, Park SY, Su J, Bailey K, Ottosson-Laakso E, Shcherbina L, Oskolkov N, Zhang E, Thevenin T, Fadista J, Bennet H, Vikman P, Wierup N, Fex M, Rung J, Wollheim C, Nobrega M, Renström E, Groop L, Hansson O: TCF7L2 is a master regulator of insulin production and processing. Hum Mol Genet 2014. [Epub ahead of print].

8. Chiang YT, Ip W, Jin T: The role of the Wnt signaling pathway in incretin hormone production and function. Front Physiol 2012, 3:273.

9. Park JR, Jung JW, Lee YS, Kang KS: The roles of Wnt antagonists Dkk1 and sFRP4 during adipogenesis of human adipose tissue-derived mesenchymal stem cells. Cell Prolif 2008, 41(6):859-874.

10. Ouchi N, Higuchi A, Ohashi K, Oshima Y, Gokce N, Shibata R, Akasaki Y, Shimono A, Walsh K: Sfrp5 is an anti-inflammatory adipokine that modulates metabolic dysfunction in obesity. Science 2010, 329(5990):454-457.

11. Ehrlund A, Mejhert N, Lorente-Cebrian S, Astrom G, Dahlman I, Laurencikiene J, Ryden M: Characterization of the Wnt inhibitors secreted frizzled-related proteins (SFRPs) in human adipose tissue. J Clin Endocrinol Metab 2013, 98(3):E503-E508.

12. Mahdi T, Hanzelmann S, Salehi A, Muhammed SJ, Reinbothe TM, Tang Y, Axelsson AS, Zhou Y, Jing X, Almgren P, Krus U, Taneera J, Blom AM, Lyssenko V, Esquerra JL, Hansson O, Eliasson L, Derry J, Zhang E, Wollheim CB, Groop L, Renström E, Rosengren $\mathrm{AH}$ : Secreted frizzled-related protein 4 reduces insulin secretion and is overexpressed in type 2 diabetes. Cell Metab 2012, 16(5):625-633. 
13. Lu YC, Wang CP, Hsu CC, Chiu CA, Yu TH, Hung WC, Lu LF, Chung FM, Tsai $I T$, Lin HC, Lee YJ: Circulating secreted frizzled-related protein 5 (Sfrp5) and wingless-type MMTV integration site family member $5 a$ (Wnt5a) levels in patients with type 2 diabetes mellitus. Diabetes Metab Res Rev 2013, 29(7):551-556.

14. Canivell S, Rebuffat S, E GR, Kostov B, Siso-Almirall A, Novials A, Ceriello A, Gomis $R$ : Circulating SFRP5 levels are elevated in drug-naive recently diagnosed type 2 diabetic patients as compared with prediabetic subjects and controls Diabetes Metab Res Rev 2014. doi:10.1002/dmrr.2599. [Epub ahead of print].

15. Carstensen M, Herder C, Kempf K, Erlund I, Martin S, Koenig W, Sundvall J, Bidel S, Kuha S, Roden M, Tuomilehto J: Sfrp5 correlates with insulin resistance and oxidative stress. Eur J Clin Investig 2013, 43(4):350-357.

16. Hu Z, Deng H, Qu H: Plasma SFRP5 levels are decreased in Chinese subjects with obesity and type 2 diabetes and negatively correlated with parameters of insulin resistance. Diabetes Res Clin Pract 2013, 99(3):391-395

17. Hu W, Li L, Yang M, Luo X, Ran W, Liu D, Xiong Z, Liu H, Yang G: Circulating Sfrp5 is a signature of obesity-related metabolic disorders and is regulated by glucose and liraglutide in humans. J Clin Endocrinol Metab 2013, 98(1):290-298.

18. Werner C, Filmer A, Fritsch M, Groenewold S, Graber S, Bohm M, Laufs U: Risk prediction with triglycerides in patients with stable coronary disease on statin treatment. Clin Res Cardiol 2014. [Epub ahead of print].

19. Alberti KG, Eckel RH, Grundy SM, Zimmet PZ, Cleeman JI, Donato KA, Fruchart JC, James WP, Loria CM, Smith SC Jr: Harmonizing the metabolic syndrome: a joint interim statement of the International Diabetes Federation Task Force on Epidemiology and Prevention; National Heart, Lung, and Blood Institute; American Heart Association; World Heart Federation; International Atherosclerosis Society; and International Association for the Study of Obesity. Circulation 2009, 120(16):1640-1645.

20. American Diabetes Association: Executive summary: standards of medical care in diabetes-2011. Diabetes Care 2011, 34(Suppl 1):S4-S10.

21. Thygesen K, Alpert JS, Jaffe AS, Simoons ML, Chaitman BR, White HD, Writing Group on behalf of the Joint ESCAAHAWHFTFftUDoMl: Third universal definition of myocardial infarction. J Am Coll Cardiol 2012, 60(16):1581-1598,

22. Anderson JL, Adams CD, Antman EM, Bridges CR, Califf RM, Casey DE Jr, Chavey WE 2nd, Fesmire FM, Hochman JS, Levin TN, Lincoff AM, Peterson ED, Theroux P, Wenger NK, Wright RS, Jneid H, Ettinger SM, Ganiats TG, Lincoff AM, Philippides GJ, Zidar JP: 2012 ACCF/AHA focused update incorporated into the ACCF/AHA 2007 guidelines for the management of patients with unstable angina/non-ST-elevation myocardial infarction: a report of the American College of Cardiology Foundation/American Heart Association Task Force on Practice Guidelines. Circulation 2013, 127(23):e663-e828.

23. Abbreviated report of a WHO consultation. Use of glycated hemoglobin $(\mathrm{HbA} 1 \mathrm{c})$ in the diagnosis of diabetes mellitus. [http://www.who.int/ diabetes/publications/diagnosis_diabetes2011/en/]

24. DECODE Study Group: Age- and sex-specific prevalences of diabetes and impaired glucose regulation in 13 European cohorts. Diabetes Care 2003, 26(1):61-69.

25. Eizirik DL, Cnop M: Mining genes in type 2 diabetic islets and finding gold. Cell Metab 2012, 16(5):555-557.

26. Bukhari SA, Shamshari WA, Ur-Rahman M, Zia-Ul-Haq M, Jaafar HZ: Computer aided screening of Secreted Frizzled-Related Protein 4 (SFRP4): a potential control for diabetes mellitus. Molecules 2014, 19(6):10129-10136.

27. Taneera J, Lang S, Sharma A, Fadista J, Zhou Y, Ahlqvist E, Jonsson A, Lyssenko V, Vikman $\mathrm{P}$, Hansson O, Parikh H, Korsgren O, Soni A, Krus U, Zhang E, Jing XJ, Esquerra JL, Wollheim CB, Salehi A, Rosengren A, Renström E, Groop L: A systems genetics approach identifies genes and pathways for type 2 diabetes in human islets. Cell Metab 2012, 16(1):122-134.

28. Ohmori S, Mori M, Shiraha K, Kawase M: Biosynthesis and degradation of methylglyoxal in animals. Prog Clin Biol Res 1989, 290:397-412.

29. Lu J, Randell E, Han Y, Adeli K, Krahn J, Meng QH: Increased plasma methylglyoxal level, inflammation, and vascular endothelial dysfunction in diabetic nephropathy. Clin Biochem 2011, 44(4):307-311.

30. Mukohda M, Okada M, Hara Y, Yamawaki H: Exploring mechanisms of diabetes-related macrovascular complications: role of methylglyoxal, a metabolite of glucose on regulation of vascular contractility. J Pharmacol Sci 2012, 118(3):303-310.

31. Lu J, Ji J, Meng H, Wang D, Jiang B, Liu L, Randell E, Adeli K, Meng QH: The protective effect and underlying mechanism of metformin on neointima formation in fructose-induced insulin resistant rats. Cardiovasc Diabetol 2013, 12:58.

32. Su Y, Qadri SM, Wu L, Liu L: Methylglyoxal modulates endothelial nitric oxide synthase-associated functions in EA.hy926 endothelial cells. Cardiovasc Diabetol 2013, 12:134.

33. Mori K, Kitazawa R, Kondo T, Mori M, Hamada Y, Nishida M, Minami Y, Haraguchi R, Takahashi Y, Kitazawa S: Diabetic osteopenia by decreased beta-catenin signaling is partly induced by epigenetic derepression of sFRP-4 gene. PLOS ONE 2014, 9(7):e102797.

34. Jacob F, Ukegjini K, Nixdorf S, Ford CE, Olivier J, Caduff R, Scurry JP, Guertler R, Hornung D, Mueller R, Fink DA, Hacker NF, Heinzelmann-Schwarz VA: Loss of secreted frizzled-related protein 4 correlates with an aggressive phenotype and predicts poor outcome in ovarian cancer patients. PLOS ONE 2012, 7(2):e31885.

35. Berndt T, Craig TA, Bowe AE, Vassiliadis J, Reczek D, Finnegan $R$, Jan De Beur SM, Schiavi SC, Kumar R: Secreted frizzled-related protein 4 is a potent tumor-derived phosphaturic agent. J Clin Investig 2003, 112(5):785-794.

36. Simpson CA, Foer D, Lee GS, Bihuniak J, Sun B, Sullivan R, Belsky J, Insogna $\mathrm{KL}$ : Serum levels of sclerostin, Dickkopf-1, and secreted frizzled-related protein- 4 are not changed in individuals with high bone mass causing mutations in LRP5. Osteoporos Int 2014, 25(10):2383-2388.

doi:10.1186/s12933-014-0155-2

Cite this article as: Hoffmann et al:: Association of secreted

frizzled-related protein 4 (SFRP4) with type 2 diabetes in patients with stable coronary artery disease. Cardiovascular Diabetology 2014 13:155.

\section{Submit your next manuscript to BioMed Central and take full advantage of:}

- Convenient online submission

- Thorough peer review

- No space constraints or color figure charges

- Immediate publication on acceptance

- Inclusion in PubMed, CAS, Scopus and Google Scholar

- Research which is freely available for redistribution

Submit your manuscript at www.biomedcentral.com/submit
C) BioMed Central 